\title{
Unidade e dispersão: os efeitos da polifonia na constituição das posições-sujeito no gênero Ata
}

\section{Unit and dispersion: the effects of polyphony on constitution of subject positions in the Minutes genre}

\author{
Recebido em: 08/10/2019 \\ Aprovado em: 25/11/2019 \\ Publicado em: 19/12/2019
}

\author{
Álvaro José da Silva Fonseca ${ }^{1}$ \\ Janete Silva dos Santos ${ }^{2}$
}

\begin{abstract}
RESUMO: Os gêneros formulaicos (ofícios, memorandos, requerimentos, relatórios, atas etc.) são subestimados em sua importância para a construção das relações discursivas institucionais. Partindo dessa posição, o presente artigo se dedica a investigar a ata - um dos gêneros formulaicos mais presentes no ambiente organizacional - considerando uma de suas caraterísticas constitutivas: a polifonia. Nosso objetivo é analisar os efeitos dessa polifonia na constituição das posições-sujeito linguisticamente marcadas pelas irregularidades em relação ao intradiscurso. Trata-se de uma pesquisa documental cujo corpus é a Ata da $72^{\underline{a}}$ reunião ordinária do Conselho Diretor do Câmpus Araguaína da Universidade Federal do Tocantins. Especificamente, analisamos a discursão do "ITEM XI - Proposta coletiva da criação da Secretaria das Coordenações de Cursos de Graduação (SEGRAD)". A escolha desse documento se deve ao fato de, como servidores da referida instituição, possuirmos acesso privilegiado às condições de produção materiais do texto, o que é fundamental dentro do campo teórico metodológico ao qual nos filiamos, a análise de discurso francesa de M. Pêcheux e E. Orlandi. De um modo geral, nossa investigação demonstra que, no recorte específico, a regularidade intradiscursiva marcada na Ata é deslocada num movimento de dispersão da posição-sujeito identificada como "prof./profa.".
\end{abstract}

Palavras-chave: Análise de Discurso; Polifonia; Ata

ABSTRACT: The formulaic genres (letters, memos, requirements, reports, minutes, etc.) are underestimated in their importance for the construction of institutional discursive relations. Based on this position, the present article is dedicated to investigate the minutes - one of the most common formulaic genres in the organizational environment - considering one of its constitutive characteristics: polyphony. Our aim is to analyze the effects of this polyphony on the constitution of subject positions linguistically marked by irregularities in relation to intradiscourse. This is a documentary research whose corpus is the minutes of the 72nd ordinary meeting of the Board of Directors of the Araguaína Campus of the Federal University of Tocantins. Specifically, we analyzed the discourse of "ITEM XI - Collective Proposal for the Creation of the Secretary of Coordination of Undergraduate Courses (SEGRAD)". The choice of this document is due to the fact that, as servants of that institution, we have privileged access to the material production conditions of the text, which is fundamental within the methodological theoretical field to which we affiliate, M. Pêcheux's French discourse analysis. and E. Orlandi. In general, our investigation demonstrates that, in the specific cut, the intradiscursive regularity marked in the minutes is displaced in a movement of dispersion of the subject position identified as "prof./profa."

Keywords: Discourse Analysis; Polyphony; Minutes

1.Graduado em Letras. Mestrado em Gestão de Políticas Públicas. Doutorando em Letras. Membro do Grupo de Pesquisa em Linguagem, Educação e Sustentabilidade. Universidade Federal do Tocantins. ORCID: 0000-0002-0268-6021. E-mail: alvaro.fonseca@uft.edu.br

2. Licenciada plena em Letras. Mestrado e doutorado em Linguística Aplicada pela Unicamp. Docente (professor adjunto III) da universidade Federal do Tocantins. ORCID: 0000-0003-2823-6114. E-mail: janetesantos@uft.edu.br 


\section{INTRODUÇÃO}

Consideramos que o ambiente universitário é antes de tudo um espaço organizacional onde diferentes perspectivas de simbolizar a realidade disputam a hegemonia do discurso institucionalizado. Circulam nessa organização alunos, servidores docentes e técnicos, além de funcionários terceirizados e visitantes que são oriundos de classes sociais distintas; reproduzem, assim, formações discursivas similares ou antagônicas; ocupam posições desiguais nas relações formais; bem como incorporam formas-sujeitos (des) legitimadas no cenário organizacional. Para nós, essa intrincada rede de sentidos se materializa nas manifestações linguístico-discursivas (semiotizadas inclusive multimodalmente, por meio de signos verbais e não-verbais) do cotidiano universitário (cartazes, aulas, avisos, editais, formulários, memorandos, e-mails, artigos, cores, gravuras etc.).

Desse modo, a nossa investigação se preocupa com a produção dos sentidos no meio universitário, concebido em seu aspecto organizacional. Para tanto, partimos de uma problemática que envolve a produção e circulação dos sentidos por meio de um dos gêneros formulaicos ${ }^{1}$, entendidos aqui simplesmente como sendo aqueles gêneros discursivos de escrita padronizada e que circulam no meio organizacional como ofícios, memorandos, requerimentos, relatórios, atas, editais etc.

Preocupa-nos a concepção normativo-prescritivista que predomina nos manuais dedicados a esse tipo de produção textual e que repercute a ilusão de transparência dos sentidos ali existentes. Isso porque tomamos o texto como como acontecimento, no qual a ideologia estabelece relação de poder. Contudo, nossa investigação está longe de ser uma tentativa de apresentar uma contraproposta de material didático para o ensino desses gêneros. Pretendemos, sim, realizar um gesto de leitura em que o texto escrito focalizado seja compreendido em sua manifestação sócio-histórico-ideológica. Ou seja, ancorados nos fundamentos teórico-metodológicos da análise de discurso francesa preconizada por M. Pecheux e E. Orlandi, procuramos realizar uma abordagem discursiva sobre o gênero formulaico, considerando o vasto horizonte que se apresenta para estudos no espaço organizacional e uma latente necessidade de se lançar luz sobre as relações de sentido materializadas nesses gêneros.

Como objeto simbólico, sobre o qual nos debruçamos, temos a ata. Esse gênero formulaico constituído por vozes de diferentes enunciadores, controladas pelo Locutor que

\footnotetext{
1 Esta denominação é encontrada nos trabalhos escritos e orientados por de E. Nascimento (2012) e carecem de uma definição mais precisa.
} 
a assina, é por nós estudada tendo como elemento central de análise a ocorrência polifônica. Mais precisamente, mobilizamos a interação entre a teoria polifônica de $\mathrm{O}$. Ducrot com a Análise de Discurso (AD). Salientamos que nosso intuito não é forçar uma aproximação epistemológica, embora seja plenamente possível, mas explorar também recursos linguístico-estilístico-discursivos apontados por O. Ducrot (1987), a fim de construir um dispositivo de análise capaz de iluminar o funcionamento discursivo e nos oferecer uma melhor compreensão acerca do movimento de constituição das posiçõessujeito na enunciação. Assim, nosso objetivo é analisar os efeitos da polifonia na constituição das posições-sujeito linguisticamente marcadas pelas irregularidades em relação ao intradiscurso materializado no texto. Em outras palavras, realizamos uma análise discursiva em que investigamos o funcionamento do recurso polifônico na constituição de posições-sujeito e buscamos compreender como o Locutor mobiliza a formação discursiva de modo a articular o intradiscurso com uma exterioridade institucional.

Nosso percurso de análise consiste em (i) desfazer a ilusão de transparência do texto; (ii) expor a materialidade do processo de significação; (iii) pontuar posições-sujeito ali (re)constituídas; e (iv) mobilizar o domínio disciplinar específico da Análise de Discurso e dos estudos semântico-argumentativos ducrotianos, referentes ao caráter polifônico constitutivo da língua(gem), para compreender os processos que afetam a produção de sentidos.

\section{REFERENCIAL TEÓRICO}

Tradicionalmente, os gêneros formulaicos são concebidos dentro de uma perspectiva normativo-prescritivista, segundo a qual seria preciso supor que os interlocutores de uma produção textual dominam a estrutura da língua, os significados das palavras e as formulações discursivas. Segundo Nascimento (2012, p. 20):

\footnotetext{
Pode-se falar que a concepção de língua e o princípio de objetividade que fundamentam os manuais de redação, além de não se sustentarem mais teoricamente, não trazem resultados eficazes nem para a análise da linguagem no universo empresarial e oficial, tampouco para o próprio uso, uma vez que mascara a própria realidade linguístico-discursiva desse universo.
}

Por meio dessa abordagem, "os manuais, tanto oficiais como os publicados sob a forma de livro, oferecem modelos de documentos, cujo fim não é nada mais do que criar padrões de interação" (idem, p. 19). Para Nascimento (2012) há um contrassenso entre a 


\section{FONSECA, Á.J.S; SANTOS, J.S}

abordagem didática centrada no ensino de modelos, formulários e procedimentos padronizados, comuns em manuais técnicos, e as expectativas em torno daqueles que atuam com a escrita no meio organizacional que precisam ser proativos, reflexivos, executar ações de gestão, assessoria e consultoria. Essa concepção está pacificada pelos manuais de redação técnica e ausente do debate acadêmico. São parcas as pesquisas preocupadas em analisar esses textos sob uma vertente linguística. Sobre isso, destacamos as contribuições de Batista e Nascimento (2009); Nascimento (2010; 2012); Nascimento e Oliveira (2011); sobre o gênero Ata, e Nascimento (2012a;2013; 2014); Nascimento e Andrade (2013); Deus e Nascimento (2013); Lima e Nascimento (2013); Nascimento e Gonçalves (2013); Santos e Nascimento (2011a,b); Gonçalves e Nascimento (2010; 2011); Batista e Nascimento (2010); acerca de outros gêneros formulaicos.

Uma das contribuições dessas pesquisas foi ratificar a noção bakhtiniana e ducrotiana de que a subjetividade é uma das diversas características constitutivas dos gêneros de discurso, dentre eles os formulaicos. Segundo os manuais, a redação técnica deve prescindir da impessoalidade, um dos princípios da administração pública e uma das regras da boa representação institucional.

A impessoalidade decorre de princípio constitucional (Constituição, art. 37), e seu significado remete a dois aspectos: o primeiro é a obrigatoriedade de que a administração pública proceda de modo a não privilegiar ou prejudicar ninguém, de que o seu norte seja, sempre, o interesse público; o segundo, a abstração da pessoalidade dos atos administrativos, pois, apesar de a ação administrativa ser exercida por intermédio de seus servidores, é resultado tão-somente da vontade estatal. (BRASIL, 2018, p. 20).

O espaço discursivo organizacional é fundamentado numa lógica estabilizante dos sentidos. Busca-se a regularidade institucional dos atos linguísticos. Nesse cenário se eliminaria o equívoco e os sentidos seriam compartilhados de modo a manter a língua imutável como um sistema perfeito de relacionamento simbólico mediado pela palavra. Para a $A D$, isso está no campo do impossível, uma vez que o referencial da língua não está no mundo, como supõem os adeptos da normatividade linguística, mas na própria língua. O "real" é concebido a partir da relação do homem com a linguagem. Os sentidos se dão num movimento de resgate da memória discursiva e reprodução ideológica que se atualiza na materialidade do texto. Em nosso gesto de interpretação consideramos que a $A D$ se propõe a expor o olhar leitor do analista à opacidade do texto. A proposta teórica nos ajuda nessa empreitada sobretudo porque trata a linguagem como uma manifestação 


\section{FONSECA, Á.J.S; SANTOS, J.S}

sócio-histórico-ideológica, condicionada às determinações do contexto de sua produção que envolvem o assujeitamento ideológico inconsciente do indivíduo (sujeito); a institucionalização das formulações discursivas próprias de uma dada organização (língua); e a materialização das relações sociais possíveis numa dada conjuntura social.

Em nossa perspectiva teórico-analítica, apoiamo-nos também na compreensão dada por O. Ducrot (1987, p.162) acerca da não-unicidade do sujeito. Desse modo, consideramos que a subjetividade é constitutiva de qualquer ato da linguagem, visto, porém, como prática e acontecimento, não como um ato individual de fala, tal qual proposto pelo filósofo John Austin. Isso porque, segundo Ducrot, mesmo que como indivíduos (pessoas 'reais'), sejamos o sujeito empírico de qualquer enunciação, linguisticamente falando e dentro de sua teoria polifônica, somos na verdade sujeitos locutores, ou seja, somos o sujeito (autor) com voz (poder para dizer) que na verdade orquestra as outras vozes (posicionamentos alheios) para construir nosso próprio "discurso" (nosso posicionamento). Assim, sempre que enunciamos, como locutores que somos, trazemos outros enunciadores (que nada mais são que pontos de vista, outras vozes) para nossos discursos, a fim de com eles concordarmos ou deles discordarmos, apontando conclusões ao nosso interlocutor. Ou seja, vamos mostrar outro ponto de vista, isto é, que discordamos de um ponto de vista dado anteriormente (trazido por nós), e, como locutor, nos identificamos com o outro ponto de vista (outra voz) também trazido por nós, por exemplo. O Locutor pode até concordar com a posição de um dos enunciadores, que insere em seu enunciado, mas também pode mostrar que se identifica com a posição de outro enunciador, também por ele inserido. Em suma, nessa perspectiva ducrotiana, como locutores, somos maestros a reger as diferentes vozes sociais, ora tocando uma mais fortemente (nos identificando com ela), ora nos afastando de outras (concordando ou discordando delas). Tal perspectiva, para Ducrot, implica dizer que a argumentação está na língua, seja pela escolha das palavras, dos torneios sintáticos, seja pelo modo como acionamos as vozes alheias e pelo modo como modalizamos nossos dizeres a fim de construir nosso texto, que é sempre polifônico, orientando o interlocutor quanto ao nosso posicionamento.

Conforme Orlandi (2008), Ducrot elabora uma distinção importante entres as duas funções enunciativas do sujeito: "a de locutor, que é aquela pela qual ele se representa como eu no discurso e a de enunciador que é (são) a(s) perspectiva(s) que esse eu constrói" (idem, p. 76-7). No gênero focalizado, recortamos o elemento subjetivo da articulação entre as vozes distintas configuradas na função de locutor. Logo, 


\section{FONSECA, Á.J.S; SANTOS, J.S}

diferenciamos o locutor principal (L), aquele que constrói todas as outras vozes, outros "eus" da enunciação. Desse modo, segundo Nascimento (2012), a polifonia é uma marca do estilo composicional da ata que se materializa na tomada de posição de outros locutores ( $L_{1}, L_{2}$, $L_{3}$ etc.).

Cada locutor enunciado na ata representa uma posição elaborada pelo $L$ para textualizar o acontecimento reunião. Por meio desse movimento de elaboração discursiva do evento é criada uma representação histórica do "real", ou seja, a ata se torna a impressão material dos fatos necessários à construção enunciativa da reunião.

Aqui cabe fazermos algumas considerações com base na teoria polifônica de Ducrot e na $A D$ aqui mobilizada, para situamos melhor o que nos interessa ressaltar de cada uma na análise do corpus. Se ter voz na sociedade implica ser 'investido', em determinado espaço, esfera, instituição (e em certas condições), de um 'direito' de dizer, de falar, de fazer uso da palavra, de se posicionar (e, consequentemente, de [re]posicionar outros), ser o locutor de um texto (a ata) é estar investido de poder para agenciar e qualificar certos enunciadores (vozes alheias, pontos de vista) e apagar ou atenuar outros, escolhidos e destacados os primeiros conforme o projeto de dizer do locutor. Tal agenciamento, na perspectiva linguístico-enunciativa de Ducrot, evidentemente não é trabalho de um sujeito uno, e, em $A D$, nem de uma consciência plena, já que, nesta área, o sujeito é cindido (ORLANDI, 2005), pois é afetado pelo inconsciente (o que é estruturado como linguagem), mobilizando formações discursivas sobre as quais não tem controle. Ducrot, como linguista, não vai se ocupar de questões da psicanálise, como as trazidas e ressignificadas para a AD por Pêcheux, mas vai mostrar como no intradiscurso (o eixo da formulação) a própria língua orienta a argumentação, pelo uso que se faz do léxico escolhido (recortado pelo universo vocabular do locutor) e, principalmente, pelo modo como se faz o encadeamento das proposições, acionando articuladores, o que implica direção de sentidos, fato que ele considera, porém, não como atitudes psicológicas do locutor, pois este não é o indivíduo, o sujeito empírico, mas sim como discursivas.

Em AD, a noção de discurso, como efeito de sentidos (ORLANDI, 2008), amplia e complexifica a análise, considerando que, mesmo que o sujeito locutor organizasse seu enunciado projetando certos efeitos com escolhas (mais ou menos) [in]conscientes, move-se em terreno escorregadio, pois arrisca-se continuamente a deslocamentos de sentidos por ele não projetados, visto o efeito para seu interlocutor poder também sempre ser outro, já que este pode mobilizar formações discursivas diferentes da mobilizada pelo 
locutor do texto, já que, nessa perspectiva, texto é um objeto simbólico constituído por incompletudes e, por isso, não se fecha. Apenas como objeto empírico o texto tem começo, meio e fim, o que é uma construção imaginária própria do funcionamento discursivo.

Desse modo, por meio da ocorrência polifônica, o locutor assume uma posiçãosujeito a partir da sua relação com as vozes manifestas na materialidade do texto. Assim, são constituídas posições-sujeito que marcam as fronteiras entre as vozes interpretadas pelo autor ${ }^{2}$ assujeitado na Ata. Esse movimento é um dos responsáveis pela unidade do gênero, produzindo efeito de completude, mas também pela dispersão dos sentidos, ou seja, algo escapa à regularidade. Com isso, chegamos ao ponto que nos interessa nesse estudo, que é analisar os efeitos da polifonia na constituição da (ir)regularidade das posições-sujeito linguisticamente marcadas pela (inter)textualização. Nossa investigação, ainda que se dedique a estudar a materialidade textual situada no universo dos gêneros formulaicos, compreende a linguagem numa perspectiva discursiva, portanto, sob uma noção materialista do sentido. Ou seja, tomamos o texto escrito como um produto determinado pelas condições materiais que possibilitam sua manifestação quanto ao acontecimento discursivo.

\section{PROCEDIMENTOS METODOLÓGICOS E ANÁLISE}

Nosso estudo é de caráter documental, de abordagem qualitativa, e tem como corpus a Ata da 72a Reunião Ordinária do Conselho Diretor do Campus Araguaína da Universidade Federal do Tocantins. A partir do gesto de leitura que realizamos, operamos um recorte no objeto discursivo situado na Ata como "ITEM XI - Proposta coletiva da criação da Secretária ${ }^{3}$ [sic] das Coordenações de Cursos de Graduação (SEGRAD)". Escolhemos esse objeto por (i) abarcar uma temática de interesse para nossa pesquisa de doutorado4; (ii) confluir acontecimentos importantes para a mudança das relações organizacionais do Campus de origem; e (iii) ser produto do meio organizacional ao qual nós atuamos como servidores, seja como técnico, seja como docente. Registramos que o documento é público e pode ser obtido por meio de uma solicitação formal à secretaria da Direção do Campus.

\footnotetext{
$2 \mathrm{O}$ estatuto de autor refere-se ao sujeito social da enunciação, aquele que encerra a função-autor discutida nos trabalhos de E. Orlandi.

${ }^{3}$ Entendemos ter havido um erro de digitação em que se pretendia registra o termo "Secretaria".

${ }^{4}$ A pesquisa de doutorado encontra-se em andamento e se dedica a estudar a constituição da memória institucional da Universidade Federal do Tocantins a partir do arquivo de atas dos Conselhos superiores da Universidade.
} 
FONSECA, Á.J.S; SANTOS, J.S

Para configurar nosso objeto de análise realizamos duas modificações que consistem em (1) abreviar os nomes dos membros que constam na Ata e (2) pôr em colchetes os números das linhas de onde foram recortados os trechos ilustrativos. Ressaltamos ainda que os negritos são oriundos do texto original e optamos por mantêlos. Por fim, nosso destaque nos recortes é feito bordeando os elementos textuais.

Nosso primeiro procedimento de análise foi situar o acontecimento discursivo nas condições materiais de sua produção. Isso é crucial para justificarmos o movimento de deslocamento dos sentidos operacionalizado pelo Locutor.

\section{Condições de produção}

A Universidade Federal do Tocantins (UFT), contexto da pesquisa, destaca-se por ser a única instituição federal de ensino superior do estado do Tocantins. A UFT possui 07 (sete) campi dispostos pelo estado, conforme ilustra a figura seguinte.

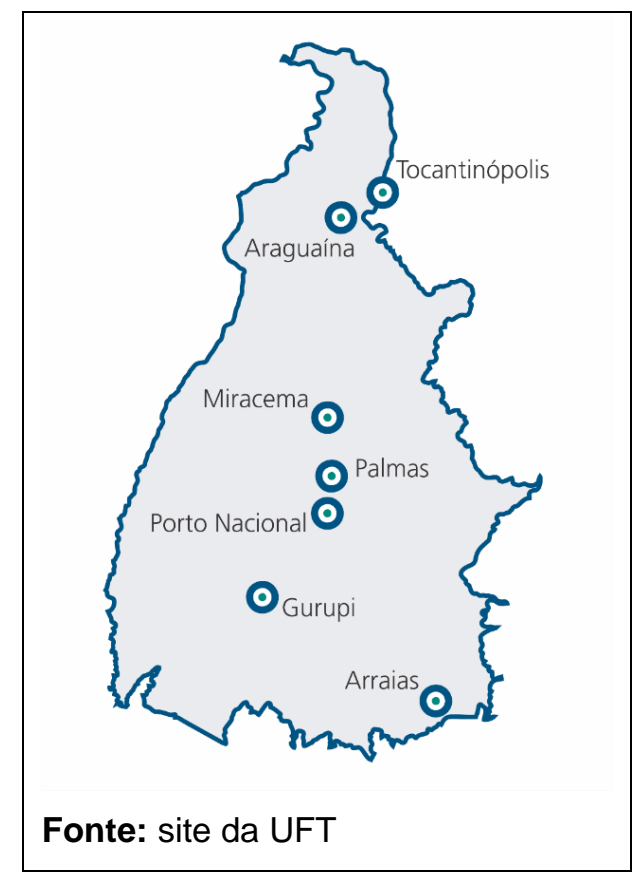

O acontecimento discursivo analisado se materializa em março de 2018, no Campus Araguaína, situado a cerca de $385 \mathrm{~km}$ de distância da Reitoria, em Palmas. Esse é um elemento importante para a constituição do nosso objeto, uma vez que à época o orçamento universitário vinha sendo reduzido em razão de uma crise econômica nacional, acentuando o distanciamento do Campus em relação à centralidade do poder institucional. A isso, somou-se a retomada de um movimento interno pelo 
FONSECA, Á.J.S; SANTOS, J.S

desmembramento da UFT ${ }^{5}$, e uma série de proposições reformistas internas tiveram espaço para serem discutidas.

Nos interessa constar que em 2016 os gestores do Campus, juntamente com os secretários de curso, iniciaram a discussão de alternativas para melhorar as relações organizacionais, dentre elas, a gestão dos processos das coordenações, definindo atribuições mais claras para os secretários. Dentre os principais motivos para essa preocupação estão os inúmeros relatos de desentendimentos entre os secretários e os coordenadores, função exercida, em tese, por docentes, que, em geral, não têm formação (acadêmica) no âmbito administrativo (gestão).

Após diversos encontros, foi instituído um grupo de estudo com os secretários para a criação de uma proposta capaz de viabilizar uma gestão mais eficiente dos processos de trabalho nas coordenações de curso. Como já dito, isso se deu num cenário de crise orçamentária, em que o governo federal realizava cortes e contingenciamentos cada vez mais severos. A equipe de administradores do Campus discutia alternativas para reduzir os gastos com a estrutura. Uma das saídas foi criar espaços compartilhados de trabalho. Esperava-se com isso aumentar a eficiência do gasto com energia elétrica e o uso mais racional de diversos equipamentos como mobiliário, computadores, condicionadores de ar, dentre outros. Ao mesmo tempo, a UFT estudava a atualização do seu organograma, criando novos setores e fundindo outros. Nesse contexto, o grupo de estudos de secretários apresentou uma proposta de padronização dos fluxos de trabalho das coordenações de curso e a integração dos secretários em um mesmo espaço, a partir de uma lógica de funcionamento diferente da existente até então. Em suma, a proposta era desvincular os secretários das coordenações e criar um setor de secretaria para atender de uma só vez a todas as coordenações. Ilustramos a proposta nas figuras seguintes:

\footnotetext{
5 Trata-se da criação da Universidade Federal do Norte do Tocantins (UFNT) por desmembramento dos campi Araguaína e Tocantinópolis que começou a tramitar em 2016 e foi sancionado em julho de 2019.
} 


\section{ANTES DA PROPOSTA}

Configuração 1

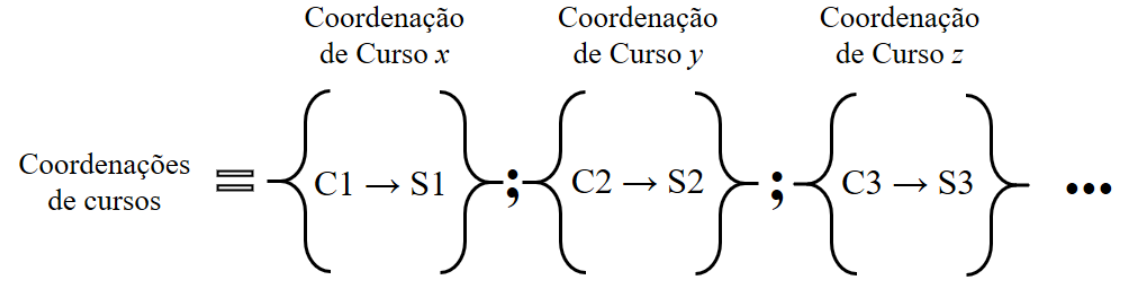

Legenda:

$C=$ Coordenador $(a)$

$S=$ Secretário $(a)$

No esquema acima, sintetizamos a configuração de como era a relação entre secretários e coordenações de cursos, ou seja, apontamos como cada coordenação tinha um respectivo secretário para atender sua demanda na própria sala da coordenação, com isso a relação entre coordenador e secretário era menos técnica e mais pessoal.

\section{DEPOIS DA PROPOSTA}

\section{Configuração 2}

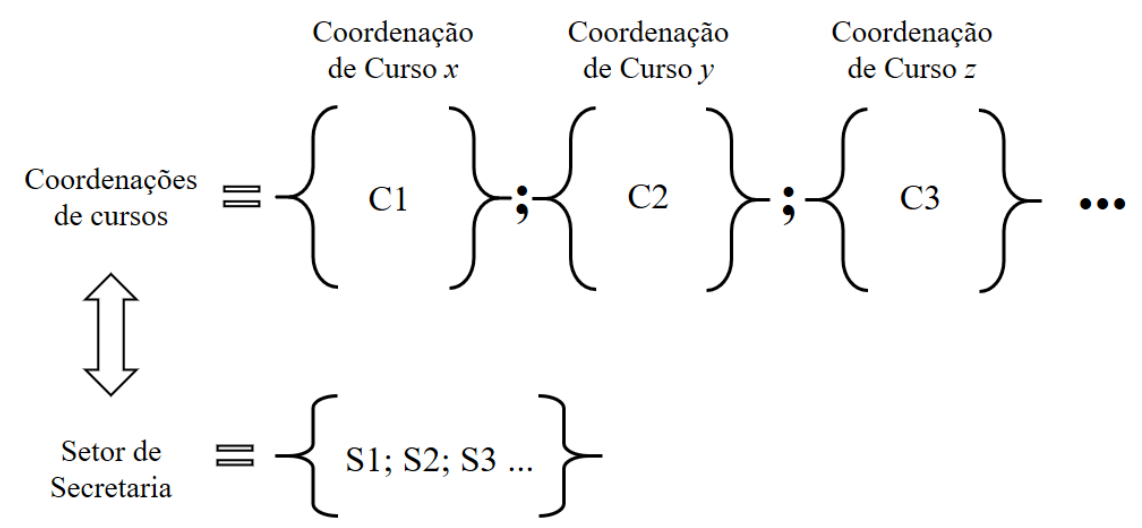

\footnotetext{
Legenda:

$C=$ Coordenador $(a)$

$S=$ Secretário $(a)$
}

Após a proposta, pelo esquema sintetizando-a acima, as coordenações (cada coordenador) de curso continuam separadas, mas o corpo de secretários passa a compor um setor específico, num espaço específico. Desse modo, cada coordenação, ao acionar 


\section{FONSECA, Á.J.S; SANTOS, J.S}

o setor dessa secretaria, poderá ser atendida por qualquer secretário, disponível em seu novo ambiente. A relação fica menos pessoal e mais técnica.

Essa proposta foi chamada de Secretaria das Coordenações de Cursos de Graduação (SEGRAD) e, de um modo geral, não foi bem recebida pelo corpo docente. Houve forte resistência de alguns coordenadores e até mesmo de colegiados inteiros. Um dos argumentos mais recorrentes contra a mudança era o de que a relação próxima coordenador-secretário se perderia, sobrecarregando os coordenadores e, consequentemente, prejudicando o andamento dos processos internos. As posições mesclavam-se entre os descontentes e os indiferentes. Era comum, ainda, a afirmação de que a decisão era discricionária da Direção do Campus e que os cursos seriam prejudicados pela gestão, não importando o que argumentassem contra a SEGRAD. A condição posta então foi a de que o Conselho Diretor do Campus Araguaína (CDA) deveria se posicionar a respeito.

Antes, porém, do projeto da SEGRAD ser encaminhado ao CDA, foram marcadas diversas reuniões entre coordenadores, secretários e Direção para alinhar a proposta. As primeiras contavam com a presença de todos os coordenadores, mas, conforme as discussões iam avançando, as reuniões foram esvaziadas pelos coordenadores até chegar ao ponto de serem ignoradas as convocações. Nesse contexto, a direção decidiu pautar o Projeto para votação no Conselho Diretor. Dessa reunião resultou a Ata do CDA, objeto de análise do presente estudo.

O CDA é a instância representativa, de caráter consultivo e deliberativo, pertencente à estrutura organizacional da UFT. Trata-se do órgão colegiado situado no topo da estrutura hierárquica em cada Campus, sendo composto pelo Diretor (como presidente), coordenadores de curso, representantes docentes, representantes discentes e representantes técnicos. Dentre os assuntos tratados no Conselho estão matérias de caráter acadêmico, como aprovação de Projeto Pedagógico de Curso e afastamentos docentes; e de gestão, como elaboração do plano orçamentário do Campus (UFT, 2004).

No âmbito institucional, a ata é um documento elaborado após as reuniões dos órgãos colegiados, a partir de registro gravado em áudio durante as reuniões, e cumpre a finalidade de registrar as deliberações dos membros sobre os assuntos constantes na pauta de discursões. A normatização interna atribui ao Secretário da Direção a responsabilidade pela redação do documento, exigindo, ainda, sua assinatura e a dos membros presentes na ata que for aprovada (UFT, 2004). 


\section{Unidade e dispersão dos sentidos}

A dinâmica organizacional por meio da qual o CDA reivindica sua existência enquanto entidade materializada no Campus constitui a regularidade do acontecimento discursivo. Toda a rede de fatos que construímos anteriormente para discursivizar as condições materiais de realização histórica do objeto analisado constituem a irregularidade marcada no recorte que operamos. Em outras palavras, o efeito de unidade na Ata decorre de uma memória de arquivo ${ }^{6}$ mobilizada intradiscursivamente em uma formação discursiva organizacional, administrativa e protocolar. Esse movimento dita as condições para a possibilidade de leitura e interpretação do texto. Quando uma memória externa desestabiliza o intradiscurso, emergem outras possibilidades de sentido que o sujeito inconsciente, afetado pela memória, deixa escapar como deslocamentos das posições-sujeitos.

A regularidade é uma manifestação discursiva responsável pelo efeito de unidade textual, enquanto a irregularidade é o que provoca dispersão da proposta de sentido. $\mathrm{O}$ intradiscurso funciona no texto por meio da formulação protocolar do gênero ata. Nesse sentido, a unidade se marca pelo recurso parafrástico que reproduz os elementos linguísticos próprios da técnica de redação desse gênero formulaico, conforme ilustra o recorte seguinte.

\section{Recorte 1}

[1] Aos vinte e sete dias do mês de março de dois mil e dezoito, às catorze horas e trinta minutos, [2] reuniram-se em sessão ordinária [...] Tendo como Presidente, Professor J.S. [4] e os(as) Conselheiros(as): A.M. (Coordenadora do Curso [5] de Letras), E.C. (Programa Profissional em Ensino de Física), M.S. [...] A reunião teve [18] como ordens do dia: ITEM I - Aprovação da Ata da 71을 reunião do CDA; ITEM II - [19] Referendar a certidão de aprovação do pedido [...] Após a leitura da pauta, o [47] Presidente solicitou a retirada do ITEM XIV, por falta de relator para o processo e solicitou [48] também a antecipação do ITEM XII. [...] Nada mais havendo a tratar eu, A.R., lavrei a presente [174] ata, que, após lida, foi aprovada e segue assinada pelo Presidente da sessão e por mim subscrita.

A partir da linearidade proposta pela estrutura genérica formulaica, a polifonia é articulada e as posições-sujeito são constituídas pelo Locutor, também parafrasticamente.

\section{Recorte 2}

[48] A Profa. S.N. solicitou a retirada do ITEM VI, pois o [49] processo não foi entregue a ela em tempo hábil para análise e emissão de parecer. O Prof. P.M. [50] solicitou a supressão do ITEM XIII, pois o regimento será discutido com os extencionistas, que [51] farão suas sugestões no documento e depois o

\footnotetext{
${ }^{6}$ Aquela que se acumula enquanto discurso institucionalizado (ORLANDI, 2012).
} 
mesmo será apresentado em reunião do CDA. O [52] Prof. T.T. sugeriu que fosse ajustada a sequência de numeração a partir do ITEM X, e que o [53] ITEM XI, fosse colocado em discussão logo após o ITEM I e o ITEM XII. As alterações na [54] pauta foram aprovadas pelo Conselho. ITEM I - Aprovação da Ata da 71ำ reunião do CDA: A [55] Ata foi aprovada, com quatro abstenções, e solicitada pelo Prof. R.A. a inclusão da [56] palavra "físico", na linha sessenta, logo após a palavra "espaço". [...] O Conselheiro J.P. [60] iniciou sua fala informando que já havia sido aprovada em outra reunião do CDA, uma comissão [61] do Câmpus de Araguaína, para analisar as normas gerais para contratos ou convênios no âmbito [62] da UFT. O Conselheiro informou que a sua fala tinha o intuito de que o Conselho Diretor do [63] Câmpus tivesse um posicionamento sobre a normativa, para que posteriormente o Prof. J.S. [64] levasse o que fosse definido em reunião, no Câmpus de Araguaína, para reunião no [65] CONSUNI. O Conselheiro fez algumas pontuações sobre o documento, esclarecendo como [66] funcionaria a viabilização de projetos no âmbito da Universidade Federal do Tocantins, bem [67] como questões financeiras relacionadas à locação do espaço físico do Câmpus, e como seria feito [68] o retorno financeiro ao Câmpus. A Conselheira F.R. informou que fez algumas sugestões na [69] normativa e que entregaria ao Prof. J.S. Ela enfatizou que após a leitura do documento [70] ficou evidente que não será mais possível, por exemplo, fazer semanas acadêmicas em que as [71] inscrições não fossem feitas por meio de GRU. O Prof. D.B. falou que se isso for aprovado, os [72] cursos, como as licenciaturas, que possuem projetos e eventos de pequeno porte, não terão [73] condições de realizar trabalhos dessa característica. [...]. [167] O Conselheiro L.A. informou que pediu [168] recapeamento da rua que dá acesso ao Câmpus e que também solicitou melhorias na iluminação [169] pública. O Conselheiro solicitou os recursos das xerox para ser realizado nas atividades [170] acadêmicas e que fará uma prestação de contas no CDA. A Conselheira E.C. informou que [171] acontecerá o $2^{\text {a }}$ Workshop em ensino de Física do Tocantins, nos dias 26 e 27 de abril. A [172] Conselheira falou sobre o conselho de ética em pesquisa do Câmpus ainda não está em [173] funcionamento. Nada mais havendo a tratar eu, A.R., lavrei a presente [174] ata, que, após lida, foi aprovada e segue assinada pelo Presidente da sessão e por mim subscrita.

A partir do Recorte 2, é possível perceber o funcionamento da regularidade intradiscursiva como uma relação parafrástica entre as posições-sujeito "prof./profa" e "Conselheiro/Conselheira". Funciona, aí, uma proposta de unidade de leitura e interpretação dessa polifonia, na qual as vozes que importam no acontecimento discursivo são aquelas legitimadas pela instituição CDA, ou seja, pelas vozes dos membros.

Essa regularidade é perturbada quando se enuncia o item $\mathrm{XI}$, em que se discute 0 projeto da SEGRAD. O efeito parafrástico da posição-sujeito "prof./profa" sofre um deslocamento em busca de uma memória externa ao acontecimento. Essa memória se faz presente na formação discursiva dos participantes da reunião, mas não se materializa na realização enunciativa adequada, qual seja, a discussão do item. Nesse momento, marcam-se as vozes favoráveis e as desfavoráveis à aprovação da SEGRAD. A posiçãosujeito "Conselheiro/Conselheira" mantém a representação de legitimidade, enquanto a posição-sujeito "prof./profa" desloca-se para o campo dos que são desfavoráveis à SEGRAD. O recorte seguinte ajuda a compreender esse movimento de cisão provocada pelo Locutor ao posicionar dois sujeitos. 


\section{Recorte 3}

[...] [94] Após a leitura o [95] Técnico-Administrativo A.J., na condição de suplente da TécnicaAdministrativa A. que [96] está em licença para qualificação, fez um resumo da proposta da SEGRAD, informando que o [97] documento da referida proposta foi encaminhado na integra para que a Direção do Câmpus [98] encaminhasse aos Conselheiros. [...]. Foi autorizada [123] a fala do Prof. O N. que não é conselheiro e que se posicionou contra a proposta. [...].

A dimensão apositiva da qual se constitui o Recorte 3 resulta da legitimação do "Técnico-Administrativo A.J.". No mesmo sentido, mas num movimento de contramão, o aposto funciona desautorizando o "Prof. N.". Conforme o contexto histórico que apresentamos anteriormente, tal interpretação se faz possível visto que se marca o afastamento à regularidade anterior que colocou na posição-sujeito "prof./profa" os locutores desfavoráveis à aprovação do projeto da SEGRAD naquela reunião.

\section{Recorte 4}

[...] [82] ITEM XI: Proposta coletiva da [83] criação da Secretária das Coordenações de Cursos de Graduação (SEGRAD). Interessado: [84] Direção do Câmpus. Relator: M.P.. Antes de começar a leitura do parecer $O$ [85] Prof. T.T. informou que foi solicitado via e-mail, vistas ao processo em discussão. No entanto, [86] O Presidente informou ao Prof. T.T. que foi pedido a cópia antecipada do parecer e que a [87] palavra "vistas" possui outro significado. O Prof. T.T. pediu que constasse em Ata que a [88] Direção use o e-mail institucional para responder aos e-mails enviados, uma vez que não foi [89] respondido à solicitação da coordenação de Química, ao pedir o acesso, antecipadamente, ao [90] parecer. [...]. A Profa. S.N. solicitou o acesso à [113] lista de servidores Técnico-Administrativos que sairão para qualificação, questionando se a [114] proporção de afastamentos não poderia ser suprida pela solicitação de novos técnicos para [115] Araguaína, pois os números na proposta da SEGRAD parecem sugerir que outras coordenações [116] ficarão sem atendimento de secretários. [...] Foi autorizada [123] a fala do Prof. O N. que não é conselheiro e que se posicionou contra a proposta. O Prof. [124] R.A. falou que é preciso levar para os colegiados discutirem a proposta para poderem rever [125] alguns pontos da proposta, ressaltando que alguns pontos da normativa precisam ser revistos, [126] para que houvesse um convencimento das coordenações. [...].

Percebemos por meio desse recorte como o mecanismo linguístico da polifonia funciona para a constituição das posições-sujeito e como a exterioridade afeta os sentidos do texto, trazendo à tona a memória discursiva que afeta o inconsciente dos sujeitos. Está aí marcada a irregularidade e a dispersão provocada pelo deslocamento dos sentidos para uma formação discursiva mobilizada pelas condições de produção da Ata, que faz irromper a formação discursiva protocolar do gênero formulaico e abre as possibilidades para novos gestos de leitura do documento constitutivo da memória institucional de arquivo. O recorte seguinte ratifica esse modo de funcionamento do discurso afetado pela exterioridade por meio da mobilização de vozes que falam em outro lugar, um lugar estranho ao CDA. 


\section{Recorte 5}

[..] [132] O Conselheiro D. enfatizou que o [133] secretário não é propriedade do curso, ele faz parte da instituição e que concorda com a criação [134] da SEGRAD. [...].

Escapa a nós a memória discursiva evocada pelo "Conselheiro D." quando afirma que "o secretário não é propriedade do curso". Reconhecemos, contudo, uma formação discursiva própria das tensões provocadas pelas contradições do modo de organização da sociedade capitalista, talvez uma memória discursiva sindicalista, em que há um processo de objetificação dos sujeitos em relação a si, de alienação do outro. Entretanto, o modo de funcionamento dessas outras vozes, embora apareçam também como marcas de rompimento da regularidade discursiva, deverá ser objeto de outra investigação tendo em vista os limites do recorte analítico do presente estudo. $O$ fato é que a exterioridade afeta as posições dos sujeitos materializadas na enunciação polifônica.

Podemos concluir, a partir do dispositivo analítico construído, que a polifonia, à medida em que funciona como elemento para constituir as posições-sujeito distintas, articula na discussão do item XI o deslocamento de sentidos afetados pela manifestação de uma exterioridade discursiva, cujos sujeitos são afetados por uma memória institucional historicamente situada. Esse movimento rompe com a regularidade dos sentidos e se materializa deslocando a equivalência parafrástica anteriormente constituída entre "prof./profa." e "Conselheiro/Conselheira".

Vale ressaltar que nos ativemos a analisar mais detidamente apenas o rompimento da regularidade desses dois pares de referências (professor/conselheiro) por nos indicarem, em nosso gesto de leitura (interpretação e compreensão de construção de sentidos), o modo pelo qual o relator da ata ora assume a posição-sujeito que corrobora a posição dos professores que fazem parte do Conselho, isto é, que são de fato conselheiros, mas concordam com o presidente da sessão, se referindo, por isso, a eles como Conselheiro, ora assume a posição-sujeito que busca deslegitimar 0 posicionamento dos professores, também conselheiros, chamando-os apenas de professores, quando estes discordam daquilo com o qual essa posição-sujeito relator da ata julga válido, já que este tende a corroborar a opinião defendida pelo presidente da sessão, que é também de seu interesse, como secretário implicado nas decisões tomadas no respectivo colegiado, cuja ata da sessão constrói e assina. 


\section{CONSIDERAÇÕES FINAIS}

Conforme Orlandi (1998, p. 74-5), analisar discursos "é aceitar a inscrição da língua na história para que haja sentido. É aceitar ao mesmo tempo que há real tanto da língua quanto da história, sendo o sentido já um gesto de interpretação e o sujeito a própria interpretação". Partindo dessa compreensão da linguagem, mobilizamos as noções de unidade e dispersão para problematizar os efeitos de sentido a partir da leitura do nosso objeto de análise.

Diferente da concepção normativo-prescritivista que recobre a produção e circulação dos gêneros formulaicos, compreendemos texto como uma proposta de sentido realizada a partir de uma orientação discursiva. Isso significa que a materialidade não é cristalina em seu "querer dizer". Pelo contrário, a unidade textual se conforma a determinadas condições de produção, que são sócio-históricas, para existir enquanto unidade de sentido (efeito ideológico). Nesse aspecto, a materialidade linguística se dispersa em possibilidades de sentido mobilizadas justamente pelas condições de sua realização material. Daí o nosso interesse em problematizar a relação unidade e dispersão dos sentidos no texto.

Neste artigo, realizamos um gesto de leitura sobre o gênero formulaico ata à luz da $A D$, apoiados também em estudos ducrotianos sobre a polifonia, investigando 0 funcionamento discursivo a partir da articulação dos locutores realizada pelo autor do texto. No recorte discursivo focalizado, compreendemos que a polifonia ressaltada pela marcação de outros locutores (ou enunciadores) no texto funciona de modo a constituir posições-sujeito distintas. Essas posições-sujeito movimentam-se entre a unidade e dispersão dos sentidos orientados pelo intradiscurso materializado na Ata.

Além das contribuições no campo da $A D$, pensamos que nossa análise também serviu para dar maior visibilidade científica aos gêneros formulaicos, muitas vezes vistos como uma espécie de subgêneros, haja vista o desprestígio deles no campo dos estudos acadêmicos.

Somos favoráveis aos esforços empregados para ampliar os estudos sobre esses gêneros por considerar relevante a compreensão do funcionamento das relações discursivas no ambiente organizacional e por mostrar que sua realização se dá num movimento que supera a concepção tradicional do texto técnico.

É preciso ressaltar ainda que nossa análise representa uma interpretação formulada a partir de um dispositivo analítico específico e que se deteve a um dos 
FONSECA, Á.J.S; SANTOS, J.S

inúmeros mecanismos de materialização da linguagem e (re)produção do discurso. Outras investigações possivelmente apontarão para caminhos diferentes do nosso. Contudo, esperamos ter, de alguma forma, contribuído para o aprofundamento dos estudos do discurso, estimulando um olhar inquieto sobre os gêneros formulaicos.

\section{REFERÊNCIAS}

BATISTA, S. L.; NASCIMENTO, E. P. A Argumentatividade no gênero ata: operadores argumentativos e modalizadores discursivos. In: VI Congresso Internacional da ABRALIN, 2009, João Pessoa. Anais - VI Congresso Internacional da Abralin. João Pessoa: Idéia, 2009. v. Único. p. 2659-2666.

BATISTA, S. L.; NASCIMENTO, E. P. Redação Comercial/Oficial e Argumentação: operadores e modalizadores no gênero relatório. In: III ENSECE-PB (Encontro de Secretariado Executivo da Paraíba), 2010, João Pessoa e Mamanguape-PB. Desenvolvendo Novas Competências. João Pessoa: Idéia, 2010. v. Único. p. 154-169.

BRASIL. Manual de Redação da Presidência da República. $3 \stackrel{a}{a}$ ed. Brasília: Presidência da República, 2018.

DEUS, K. R. A. G.; NASCIMENTO, E. P. O processo de ensino-aprendizagem de produção escrita do gênero memorando, a partir de sequências didáticas. In: III Encontro Nacional Acadêmico de Secretariado Executivo, 2013, João Pessoa. ANAIS do III Encontro Nacional Acadêmico de Secretariado Executivo - O conhecimento científico e as novas tecnologias em secretariado: relevância e impacto social. João Pessoa: Idéia, 2013. v. Único. p. 440-456.

DUCROT, O. O dizer e o dito. Campinas, SP: Pontes, 1987.

GONCALVES, K. R. A.; NASCIMENTO, E. P. Comunicação Escrita em Secretariado: a argumentação na carta comercial. In: II ENASEC Encontro Nacional Acadêmico de Secretariado Executivo, 2011, Passo Fundo-RS. A Evolução da profissão por meio da pesquisa. Passo Fundo: UFP, 2011. v. Único. p. 01-17.

GONCALVES, K. R. A.; NASCIMENTO, E. P. Estratégias Argumentativas nas Cartas Comerciais. In: III ENSECE-PB (Encontro de Secretariado Executivo da Paraíba), 2010, João Pessoa. Desenvolvendo Novas Competências. João Pessoa: Idéia, 2010. v. Único. p. 73-84.

LIMA, G. B.; NASCIMENTO, E. P. A modalização avaliativa no gênero textual discursivo requerimento: marcas de subjetividade. In: III Encontro Nacional Acadêmico de Secretariado Executivo, 2013, João Pessoa. ANAIS do III Encontro Nacional Acadêmico de Secretariado Executivo - O conhecimento científico e as novas tecnologias em secretariado: relevância e impacto social. João Pessoa: Idéia, 2013. p. 411-424.

NASCIMENTO, E. P. (org). A argumentação na redação comercial e oficial: estratégias semântico-discursivas em gêneros formulaicos. João Pessoa: Editora Universitária da UFPB, 2012. 
FONSECA, Á.J.S; SANTOS, J.S

NASCIMENTO, E. P. A Polifonia de Locutores como Estratégia Semântico-Argumentativa no

Gênero Ata. In: IX Encontro Nacional de Interação em Linguagem Verbal e Não Verbal, 2010, João Pessoa. Caderno de Resumos - IX ENIL. João Pessoa: Editora Universitária da UFPB, 2010. p. 93-94.

NASCIMENTO, E. P. A polifonia de locutores no gênero ata: estratégia semânticoargumentativa. Desenredo (PPGL/UPF), v. 8, p. 112-130, 2012.(a)

NASCIMENTO, E. P. A polifonia nos gêneros acadêmicos e formulaicos: a construção de sentidos a partir da evocação da palavra alheia. In: XXV Jornada Nacional do GELNE, 2014, Natal RN. Anais da XXV Jornada Nacional do GELNE. Natal-RN: EDUFRN, 2014. p. 01-14.

NASCIMENTO, E. P. La argumentación en los géneros de los universos empresarial y oficial: los modalizadores discursivos. In: II Congreso Internacional de Profesores de Lenguas Oficiales del MERCOSUR, 2014, Buenos Aires. Libro de actas II CIPLOM. Buenos Aires: Casa do Brasil, 2013. v. Único. p. 1488-1498.

NASCIMENTO, E. P.; ANDRADE, L. H. S. A produção textual mediada por sequências didáticas: uma experiências com gêneros formulaicos. In: II Congreso Internacional de Profesores de Lenguas Oficiales del MERCOSUR, 2014, Buenos Aires. Libro de actas II CIPLOM. Buenos Aires: Casa do Brasil, 2013. v. ùnico. p. 573-584. NASCIMENTO, E. P.; GONCALVES, Y. S. O gênero do discurso resolução: características semântico-argumentatiivas. In: III Encontro Nacional Acadêmico de Secretariado Executivo, 2013, João Pessoa. ANAIS do III Encontro Nacional Acadêmico de Secretariado Executivo - O conhecimento científico e as novas tecnologias em secretariado: relevância e impacto social. João Pessoa: Idéia, 2013. p. 425-439.

NASCIMENTO, E. P.; OLIVEIRA, P. R. S. As estratégias polifônicas no gênero ata com locutores identificados como secretários. In: II ENASEC Encontro Nacional Acadêmico de Secretariado Executivo, 2011, Passo Fundo-RS. A Evolução da profissão por meio da pesquisa. Passo Fundo: UFP, 2011. v. Único. p. 01-17.

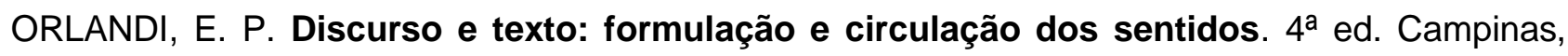
SP: Pontes. 2012.

ORLANDI, E. P. Discurso e argumentação: um observatório político. Fórum linguístico, Florianópolis, n. 1 (73-81), jul.-dez. 1998

ORLANDI, E. P. Discurso e Leitura. 8aㅡ ed. São Paulo: Cortez, 2008.

ORLANDI, E. P. Análise do discurso: princípios e procedimentos. Campinas/SP: Pontes, 6a edição, 2005.

SANTOS, S. M. C.; NASCIMENTO, E. P. O gênero edital e suas características linguísticodiscursivas: para além dos manuais de redação. In: II ENASEC Encontro Nacional Acadêmico de Secretariado Executivo, 2011, Passo Fundo-RS. A Evolução da profissão por meio da pesquisa. Passo Fundo: UPF, 2011 (b). v. Único. p. 01-12. 
FONSECA, Á.J.S; SANTOS, J.S

SANTOS, S. M. C.; NASCIMENTO, E. P. Os modalizadores como estratégia semânticoargumentativa no gênero edital. In: VII Seminário Nacional sobre Ensino de Língua Materna e Estrangeira e de Literatura, 2011, Campina Grande. ANAIS VII Seminário Nacional sobre Ensino de Língua Materna e Estrangeira e de Literatura. Campina Grande: Universidade Federal de Campina Grande, 2011 (a). v. Único. p. 112-126.

UNIVERSIDADE FEDERAL DO TOCANTINS (UFT). Resolução do Conselho Universitário da UFT n 012/2004. Aprova a criação do Regimento Interno do Conselho Diretor do Campus de Araguaína. Palmas: 2004. Disponível em: < https://docs.uft.edu.br/share/proxy/alfresconoauth/api/internal/shared/node/p42H2b32RsqXUR7bztm3sQ/content/12-2004\%20-

\%20Regimento\%20Interno\%20Conselho\%20Diretor\%20Campus\%20Aragua\%C3\%ADna.pdf>. Acesso em: 21 set. 2019.

Como citar este artigo (ABNT)

FONSECA, Á.J.S; SANTOS, J.S. Unidade e dispersão: os efeitos da polifonia na constituição das posições-sujeito no gênero Ata. SELL, Uberaba, MG, v. X, n. X, p. XXXXXX, 2019. Disponível em: <inserir link de acesso>. Acesso em: inserir dia, mês e ano de acesso. DOI: inserir link do DOI.

Como citar este artigo (APA)

FONSECA, Á.J.S; SANTOS, J.S. (2019). Unidade e dispersão: os efeitos da polifonia na constituição das posições-sujeito no gênero Ata. SELL, X(X), XXX-XXX. Recuperado em: inserir dia, mês e ano de acesso de inserir link de acesso. DOI: inserir link do DOI. 